\title{
Socio-psychological and Economic Constraints Faced by Women Beneficiaries Registered in Janani Suraksha Yojana in Samastipur District of Bihar, India
}

\author{
Ruby Kumara*, Kumari Shipra and Seema Kumari
}

\begin{abstract}
Department of Home Science Extension and Communication Management College of Community Science, DRPCAU, Pusa Samastipur Bihar, India
\end{abstract}

*Corresponding author

Keywords

Socio-

Psychological and

Economic

constraints, Women

health, JSY

\section{Article Info}

Accepted:

20 June 2020

Available Online:

10 July 2020
This paper explores the Socio-Psychological and Economic constraints faced by women beneficiaries registered in Janani Suraksha yojana. Health is a vital indicator of human development. Every minute of life every day, somewhere in the world and most often in developing countries, a woman dies for complication during pregnancy or childbirth. Pregnancy-related complications are among the leading causes of death and disability for women aged between fifteen to forty six years in developing countries. Pregnancy and childbirth are special events in women's lives as well as in their families and that can be the time of great hope and joyful participation. For this study, we used a questionnaire to collect primary data, Secondary data were also used. This study was conducted in samastipur district of Bihar. For this purpose sixty respondents were purposively selected who were registered in Janani Suraksha Yojana. The finding of the showed that the majority of the beneficiaries $(56.7 \%)$ belonged to young age group, major constraints faced by women beneficiaries were male dominance society \& their percentage value (86.6 per cent) were ranked first and lack of own business as the percentage score of this constraints were ( 85 per cent) which ranked first.

\section{Introduction}

India has a shockingly high maternal mortality rate (MMR) and infant mortality rate (IMR) of every 100000 births. In India the Maternal Mortality rate was 254 per 100000 live births in (2005), which has been reduced to 174 per 100000 live births in 2015 . Maternal Mortality rate of Bihar per 100000 live births was 312 in (2005), which has been reduced to 208 in 2016. The government target to bring maternal mortality ratio (MMR) to 100 by 2020 through various scheme and awareness programme such as Janani Suraksha Yojana. Reproductive health is a crucial part of general health and a central feature of human development. More than three quarters of the population of our country 
live in rural areas. Maternal and neonatal mortality and morbidity continue to be high despite the existence of national programs for improving maternal and child health $(\mathrm{MCH})$ in India.

Maternal and Child Health issues still continue to be a national and global health issue. Around eight million women suffer pregnancy-related complications and over half a million die every year. Pregnancy and childbirth are special events in women's lives as well as in their families and that can be the time of great hope and joyful anticipation. However, in many families, these events may become a symbol of sorrow and grief where mothers depart from their babies and families because of inadequate and poor or nil maternal health services provided to these innocent mothers. These maternal deaths could be prevented by applying simple preventive measures. Preventable maternal deaths indicate gross violation of the basic human right of survival and highlight gross failure of health services on almost all fronts particularly in terms of choice of strategic interventions and their extent of coverage in population. Antenatal care (ANC) refers to pregnancy-related healthcare, which is usually provided by a doctor, an ANM, or another health professional. Ideally, antenatal care should monitor a pregnancy for signs of complications, detect and treat pre-existing and concurrent problems of pregnancy, and provide advice and counseling on preventive care, diet during pregnancy, delivery care, postnatal care, and related issues. Antenatal care among pregnant women is one of the important factors in reducing maternal mortality and morbidity. In India, the Reproductive and Child Health scheme aims at providing antenatal check-ups which should include a weight and blood pressure check, abdominal examination, immunization against tetanus, iron and folic acid prophylaxis, as well as anemia management.
Antenatal Care has a tremendous impact on the health of the mother and child. However, good quality antenatal care is not uniformly distributed in society. Concerned particularly with the maternal and neonatal health, the Government of India (GOI) launched various schemes to promote institutional deliveries from time to time. One such new maternity benefit scheme is Janani Suraksha Yojana.

The Government of India had launched Janani Suraksha Yojana (JSY) on April 12, 2005 as a part of the National Rural Health Mission (NRHM), to ensure safe motherhood and to reduce maternal and neonatal mortality. One such new maternity benefit scheme is Janani Suraksha Yojana - JSY (In Hindi Language, Janani Mother, Suraksha =Protection, Yojana $=$ Scheme). The main objectives of JSY scheme were to reduce Maternal Mortality Rate (MMR) and Infant Mortality Rate (IMR) through encouraging institutional deliveries; particularly in below poverty line families. Under this scheme cash incentives are given to women who opt for institutional deliveries and also to the local health functionary who motivates the family for institutional delivery and helps them in obtaining ante-natal and post-natal services. The main components of the scheme are mobilizing the community with the help of intervention worker and providing cash assistance as an incentive for institutional delivery as a mean to reduce maternal and neonatal death.

The main objectives of this study includes to Know about Socio- psychological and Economic constraints faced by women beneficiaries registered in Janani Suraksha Yojana.

\section{Materials and Methods}

For this study we used a questionnaire to collect primary data, Secondary data were also used. This study was conducted in 
samastipur district of Bihar. In JSY registered women beneficiaries faced Sociopsychological and Economic constraints. For this purpose sixty respondents were purposively selected who were registered in Janani Suraksha Yojana. In Samastipur district out of which two blocks viz. Pusa and Kalyanpur were selected purposively. Out of these two blocks four villages from each block were selected randomly for study. From Pusa Block, Harpur and Mahmadda were selected and from Kalyanpur block, saidpur and Malinagar were selected purposively. Thirty beneficiaries from Pusa block and thirty beneficiaries from Kalyanpur block were selected as sample for data Collection. The data were collected with the help of a personal interview scheduled. The selected respondents were interviewed personally with the help of a well structured and personal interview schedule in order to get relevant information and to draw conclusion.

\section{Results and Discussion}

Socio- personal characteristics of the women beneficiaries Table no 1 , revealed that majority of the beneficiaries $(56.7 \%)$ belonged to young age group, belonging to 'Economically Backward Classes' (36.7\%), occupation engaged in household work
$(63.3 \%)$, their educational qualification (35\%), the beneficiaries majority of them belonged to nuclear family $(70 \%)$, the beneficiaries nearly $(48.3 \%)$ had income ranging from (Rs 50,001 to 75,000) medium income group.

Under the socio-psychological constraints the specific constraints faced by women beneficiaries in the JSY scheme were lack of motivation, rude attitude of staff, social customs and tradition, lack of family encouragement, negative social attitude towards women capabilities, male dominance society, cultural reason and joint decision in the house.

Table 2 clearly indicates that among the above constraints the major constraints faced by women beneficiaries were male dominance society $\&$ their percentage value (86.6 per cent) were ranked first. Negative social attitudes towards women's capabilities (81.6 per cent) as second rank, cultural reasons (78.3 per cent), social customs and tradition (73.3 per cent), lack of motivation (65 per cent), lack of family encouragement (63.3 per cent), rude attitude of staff ( 45 per cent) and joint decision in the house (35 per cent) were ranked as I $^{\text {st }}$ to VIII $^{\text {th }}$ respectively.

Table.1 Distribution of Percentage of the women beneficiaries on the basis of Socio-Personal characteristic

\begin{tabular}{|l|l|c|c|c|}
\hline SI.No & $\begin{array}{l}\text { Independent } \\
\text { variables }\end{array}$ & Category & Frequency(f) & $\begin{array}{l}\text { Percentage } \\
\text { (\%) }\end{array}$ \\
\hline 1. & Age & 18 to 45 years & 34 & 56.7 \\
\hline $\mathbf{2 .}$ & Caste & EBC & 22 & 36.7 \\
\hline $\mathbf{3 .}$ & Occupation & House wife & 38 & 63.3 \\
\hline $\mathbf{4 .}$ & Education & High school & 21 & 35 \\
\hline $\mathbf{5 .}$ & Family type & Nuclear family & 42 & 70 \\
\hline 6. & Family annual income & Medium (Rs 50,001 to 75,000) & 29 & 48.3 \\
\hline
\end{tabular}


Table.2 Frequency and percentage distribution of respondents with respect to their sociopsychological constraints faced by women beneficiaries

\begin{tabular}{|l|c|c|c|}
\hline \multicolumn{1}{|c|}{ B. Problems and constraints } & \multicolumn{2}{c|}{$\begin{array}{c}\text { Pusa and Kalyanpur block } \\
\text { ( N=60) }\end{array}$} & \multirow{2}{*}{ Rank } \\
\cline { 2 - 3 } & Frequency & Percentage \\
\hline Socio-Psychological constraints & $\mathbf{3 1 7}$ & $\mathbf{6 6 . 0 4}$ & \\
\hline Lack of motivation & 39 & 65 & V \\
\hline Rude attitude of staff & 27 & 45 & VII \\
\hline Social customs and tradition & 44 & 73.3 & IV \\
\hline Lack of family encouragement & 38 & 63.3 & VI \\
\hline Negative social attitude towards women's capabilities & 49 & 81.6 & II \\
\hline Male dominance society & 52 & 86.6 & I \\
\hline Cultural reasons & 47 & 78.3 & III \\
\hline Joint decision in the house & 21 & 35 & VIII \\
\hline
\end{tabular}

Table.3 Frequency and percentage distribution of respondents with respect to their economic constraints faced by women beneficiaries

\begin{tabular}{|l|c|c|c|}
\hline \multirow{2}{*}{ Problems and constraints } & \multicolumn{2}{|c|}{ Pusa and Kalyanpur block } & \multirow{2}{*}{ Rank } \\
\cline { 2 - 4 } & Frequency & Percentage & \\
\hline Economic constraints & $\mathbf{2 1 2}$ & $\mathbf{7 0 . 6}$ & \\
\hline Lack of money in house & 47 & 78.3 & II \\
\hline Lack of income source & 39 & 65 & IV \\
\hline Lack of cooperation from family income & 42 & 70 & III \\
\hline Non availability of money at time & 33 & 55 & V \\
\hline Lack of own business & 51 & 85 & I \\
\hline & & & \\
\cline { 1 - 3 } & & &
\end{tabular}

Fig.1

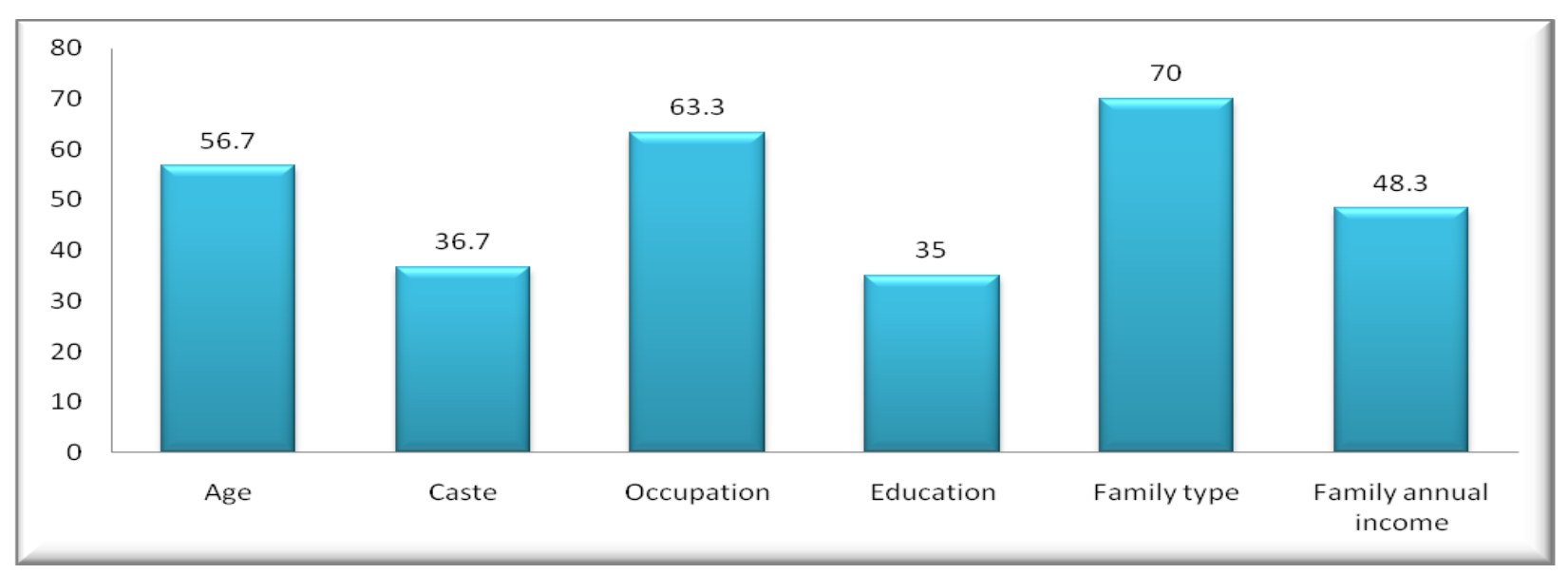


Fig.2

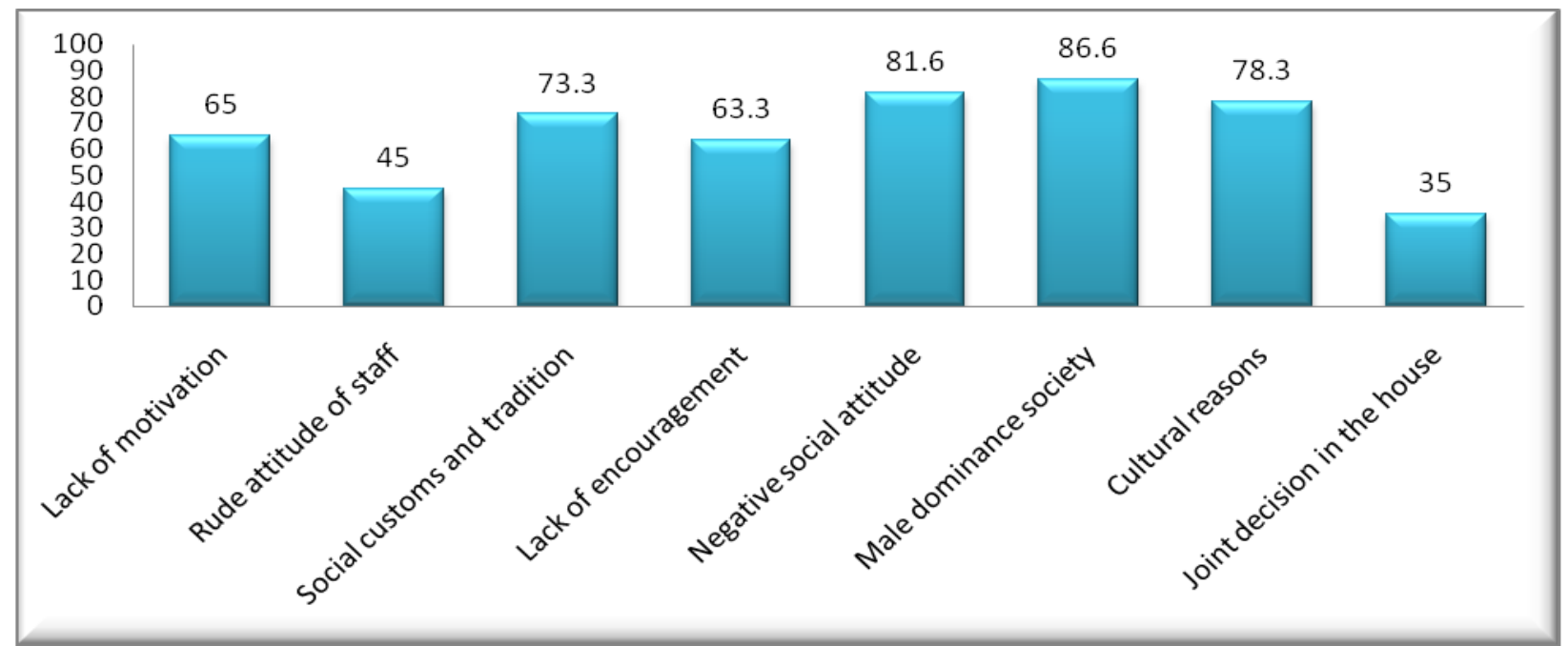

Fig.3

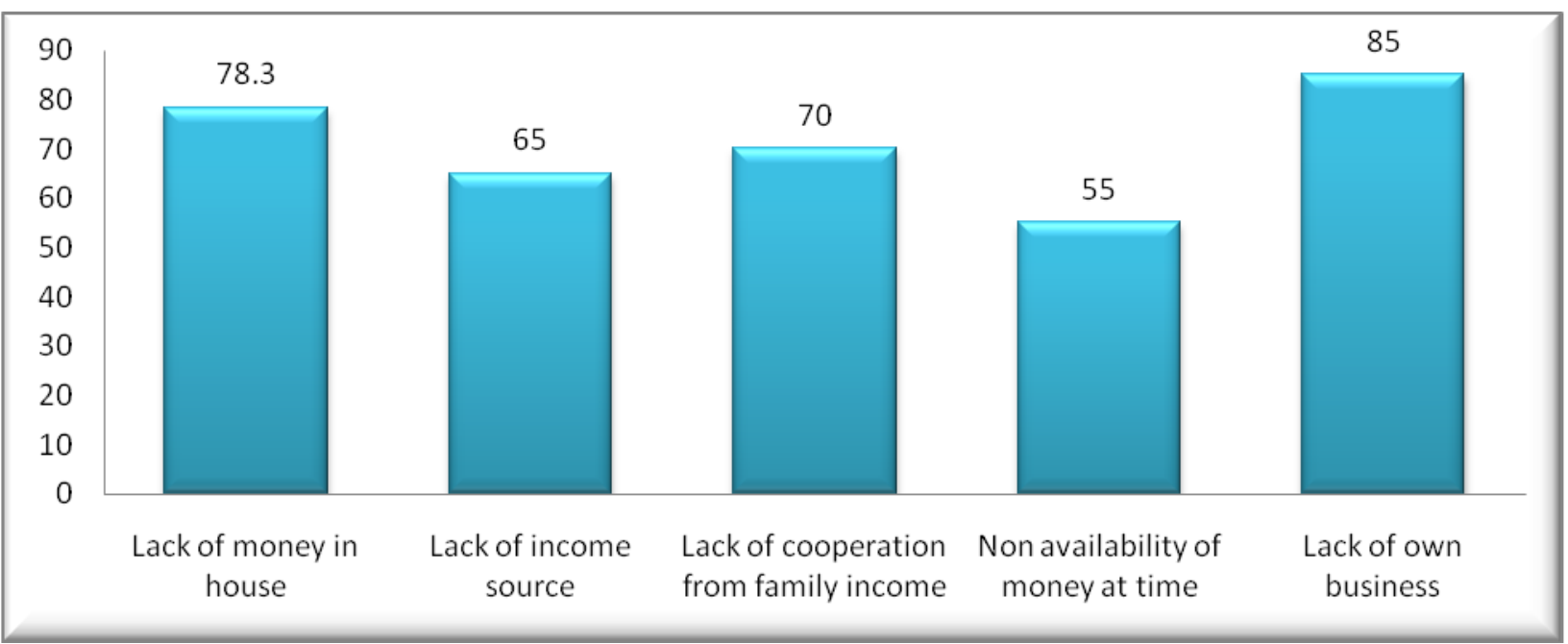

The different economic constraints which were directly and indirectly responsible as constraints for utilizing well JSY service either in antenatal and post natal stages are listed in table. Using frequency, percentage and ranking technique are given in the following table.

The observation of the table 3 clearly revealed that the majority of the respondents faced the constraint's lack of own business as the percentage score of this constraints were (85 per cent) which ranked first. Lack of money in house(78.3 per cent),lack of cooperation from family income(70 per cent), lack of income source(65 per cent) and non availability of money at time (55 per cent) were ranked as Its to $\mathrm{V}^{\text {th }}$ respectively.

In conclusion, the finding of study showed that the apart from the fact and assumption that women beneficiaries have many problems in their life. The findings of the study showed that the major constraints for JSY beneficiaries were Socio-Psychological such as male dominance society (86.6 per 
cent) and economic constraint like lack of money in house (78.3 per cent) among the study variables such as (Age, cast, Occupation, Education, Family type, Family annual income). The literacy of women is the key to improve health status and overcome their health constraints. Education and communication activities are specially organized in rural areas with the purpose of reduce maternal constraints. The NRHM raised a cadre of trained women community health workers called ASHA (Accredited Social Health Activist) who play an important role in implementing the JSY at the grassroots level and motivate the family members for obtaining institutional delivery and to help about reduce socio psychological constraints such as negative social attitude towards women's capabilities and male dominance society. Economic constraints such as lack of source of income and lack of own business major constraints have women beneficiaries.

\section{References}

1. Bhimani, N.R., Vachhani, P.V., Kartha. G.P. (2016). Utilization pattern of antenatal health care services among married of reproductive age group in the rural area of surendranagar district, Gujarat, India: A community based crass sectional study. International Journal of Research in Medical Sciences, 4(1): 252-
261.

2. Doke, P.P., Gawande, U.H., Deshpande, S.R., Gadgil, M. (2015). Evaluation of JSY in Maharashtra, India: Important lessons for implementation. International Journal of TROPICAL Diseases and health, 5(2):141-155.

3. Gupta, S.K., Pal, D.K., Tiwari, R., Garg, R., Sarawagi, R., Shrivastava, A.K., Gupta, P. (2011). Assessment of JSY in Jabalpur, Madhya Pradesh: Knowledge, attitude \& utilization pattern of beneficiaries: a descriptive study. International Journal of current Biological and Medical Science, 1(2): 611.

4. Radhika, M., Krishna, A.V., Indira, S. (2015). Knowledge and utilization practices of reproductive and child health services among mothers. International Journal of Applied Research, 1(8): 428432.

5. Veena Chandavari and Chhaya Badiger. (2013). National Rural Health Mission: Impact on rural mothers and children. Karnataka Journal of Agricultural Science., 26(1): 133-137.

6. Wadgave Hanmanta Vishwanath, Gajannan M Jatti, Upendra Tannu (2011) Missed Opportunities of Janani Suraksha Yojana benefits among the beneficiaries in slum areas. National Journal of Community Medicine, 2(1): 40-42.

\section{How to cite this article:}

Ruby Kumara, Kumari Shipra and Seema Kumari. 2020. Socio-psychological and Economic Constraints Faced by Women Beneficiaries Registered in Janani Suraksha Yojana in Samastipur District of Bihar, India. Int.J.Curr.Microbiol.App.Sci. 9(07): 2406-2411. doi: https://doi.org/10.20546/ijcmas.2020.907.281 